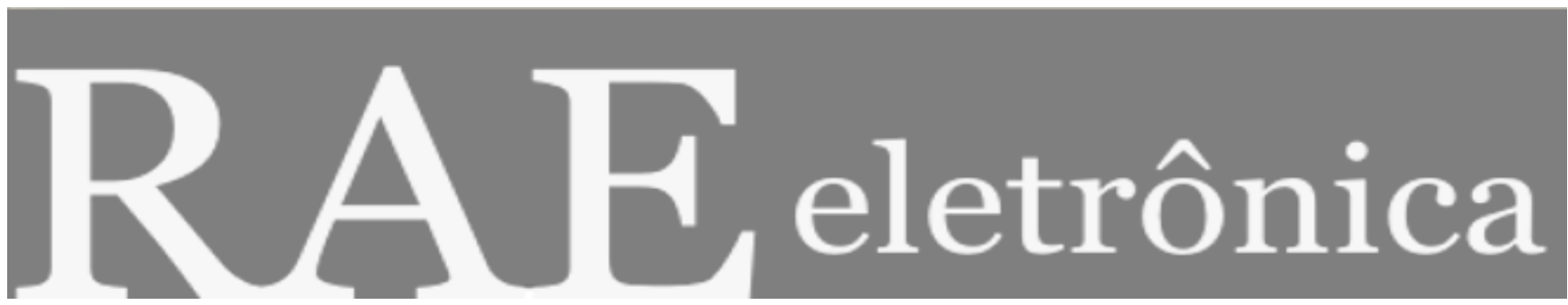

\title{
LEI DE RESPONSABILIDADE FISCAL: CONDIÇÃO INSUFICIENTE PARA O AJUSTE FISCAL
}

Por:

\section{Antônio Carlos de Azevedo Sodré}

RAE-eletrônica, Volume 1, Número 2, jul-dez/2002.

http://www.rae.com.br/eletronica/index.cfm?FuseAction=Artigo\&ID=1461\&Secao=EMPRESA\%20JR $\&$ Volume $=1 \&$ Numero $=2 \& A n o=2002$

CCopyright, 2002, RAE-eletrônica. Todos os direitos, inclusive de tradução, são reservados. É permitido citar parte de artigos sem autorização prévia desde que seja identificada a fonte. A reprodução total de artigos é proibida. Os artigos só devem ser usados para uso pessoal e nãocomercial. Em caso de dúvidas, consulte a redação: redacao@,rae.com.br.

A RAE-eletrônica é a revista on-line da FGV-EAESP, totalmente aberta e criada com o objetivo de agilizar a veiculação de trabalhos inéditos. Lançada em janeiro de 2002, com perfil acadêmico, é dedicada a professores, pesquisadores e estudantes. Para mais informações consulte o site www.rae.com.br/eletronica.

RAE-eletrônica

ISSN 1676-5648

(C)2002 Editora: Fundação Getulio Vargas - Escola de Administração de Empresas de São Paulo.

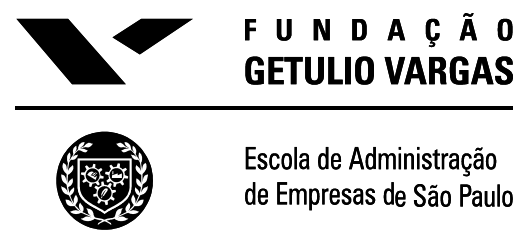




\title{
LEI DE RESPONSABILIDADE FISCAL: CONDIÇÃO INSUFICIENTE PARA O AJUSTE FISCAL
}

\author{
Antônio Carlos de Azevedo Sodré \\ Bacharel em Administração Pública pela FGV-EAESP \\ E-mail: antoniocsodre@hotmail.com \\ Endereço: R. Vicente Leporace, no. 450 - Campo Belo São Paulo, SP. \\ Interesses de pesquisa: Macroeconomia, Política Fiscal, Política Monetária, Finanças Públicas.
}

\section{RESUMO}

O estudo aqui exposto tem como objetivo discutir a Lei de Responsabilidade Fiscal (LRF) do ponto de vista de sua relevância para o ajuste fiscal brasileiro. Para isto, são apresentados os principais dispositivos desta lei, explorando os seus possíveis impactos nas contas públicas brasileiras nos próximos anos. A análise é feita com base em um referencial teórico que, apesar de simples, é de muita utilidade para o estudo das questões fiscais pois enfatiza a relação das variáveis que influenciam diretamente na evolução da Dívida Pública. Com base neste referencial e no breve exame dos resultados fiscais apresentados pelo país durante o Plano Real argumenta-se que a LRF não garante o equilíbrio fiscal brasileiro pois ela não exerce um controle significativo nos gastos financeiros do setor público.

\begin{abstract}
The study displayed here has as objective to discuss beyond Fiscal Responsibility Law (FRL) from the point of view of its relevance for the Brazilian fiscal adjustment. For this, the main devices of this law are presented exploring their possible impacts in the Brazilian public accounts in the next years. The analysis has been made based upon a theoretical reference that although simple it is extremely useful for the study of fiscal questions, therefore emphasizes the interrelation of the variables which influence directly in the evolution of the public debt. Based on this reference and on the brief examination of the fiscal results presented by the country during the Plano Real it argues that the FRL does not guarantee the Brazilian fiscal balance therefore it does not exercise a significant control in the financial expenses of the public sector.
\end{abstract}

\section{PALAVRAS-CHAVE}

Lei de responsabilidade fiscal, política fiscal, dívida pública, ajuste fiscal, contas públicas.

\section{KEY WORDS}

Fiscal responsibility law, fiscal policy, public debt, fiscal adjustment, public accounts. 


\section{INTRODUÇÃO}

A questão do ajuste fiscal, ao menos nos últimos 20 anos, esteve constantemente presente no debate econômico brasileiro. Na década de 80, o consenso formado ressaltava o ajuste fiscal como requisito fundamental para a estabilização monetária (GIAMBIAGI, 1997). Entretanto, a prática do Plano Real mostrou que o controle da inflação poderia se sustentar mesmo com a deterioração fiscal ocorrida após 1994. Não se pode negar que no lançamento do plano vivia-se em uma situação de "ajuste fiscal" temporário, ou seja, balizado em medidas de curto prazo que não se sustentaram ao longo do tempo. Todavia, alguns autores como FRANCO (2000), destacavam a importância do controle do déficit público como forma de sustentar a estabilização.

Os dados referentes à evolução das contas públicas brasileiras ao longo do Plano Real demonstram que o país caminhou longe do ajuste físcal. Depois do ano de 1994, quando o superávit primário do setor público foi de 5,21\% do Produto Interno Bruto, o período 1995/1998 foi marcado por um déficit primário médio de $0,2 \%$ do PIB e por um déficit nominal médio de 5,41\% do PIB. Para o biênio 1999/2000, os dados indicam uma melhora dos resultados primário e nominal. O superávit primário médio deste período foi de 3,38\% do PIB e o déficit nominal médio foi de 4,59\%, os melhores resultados desde 1995. Entretanto, a Dívida Líquida do Setor Público apresentou uma trajetória crescente ao longo de todos os anos do Plano Real. Em janeiro de 1994, esta dívida representava $31,11 \%$ do PIB. Em julho de 2001 a mesma já representava 52,82\% do PIB.

É inegável o papel da política de estabilização monetária imposta pelo Plano Real na piora dos resultados físcais e no crescimento da dívida pública a partir de 1994. A ancoragem cambial, um dos pilares do programa de estabilização, e a conseqüente elevação da taxa de juros contribuíram, de forma decisiva, para o aumento das despesas financeiras do setor público no período.

A partir do final de 1998, com a eminente desvalorização cambial e, posteriormente, com o acordo junto ao Fundo Monetário Internacional, o governo central retoma o discurso da necessidade do equilíbrio das contas públicas. Em 1998, é lançado o Programa de Estabilidade Fiscal Brasileiro. Este programa tem como premissa, que “ ... o Estado não pode viver além dos seus limites, gastando mais do que arrecada." (MINISTÉRIO DA FAZENDA, 1998). Este programa discorria, também, sobre uma lei que “...definirá princípios básicos de responsabilidade, derivados da noção de prudência na gestão dos recursos públicos, bem como limites específicos referentes a variáveis como nível de endividamento, déficit, gastos e receitas anuais".

Em 4 de maio de 2000, como resultado direto do Programa de Estabilização Fiscal, entrou em vigor a Lei de Responsabilidade Fiscal (LRF), com objetivos explícitos de estabelecer uma coordenação das políticas físcais de todos os entes da federação e de afirmar no país o equilíbrio fiscal como obrigação da administração pública.

O objetivo deste estudo é analisar os principais aspectos desta lei, avaliando a sua capacidade de conduzir o país para uma situação de ajuste fiscal. Para atingir tal objetivo, este artigo está estruturado em quatro seções. Na primeira parte são apresentados os principais dispositivos e princípios da LRF. As principais referências utilizadas para esta exposição são: TRIBUNAL DE CONTAS DO RIO GRANDE DO SUL (2000), KHAIR (2000), AFONSO (1999) e FIGUEIREDO e NÓBREGA (2000). Logo após, é introduzido o referencial teórico de análise para, posteriormente, ser encaminhado um exame das contas públicas brasileiras durante o Plano Real. Finalmente, serão apresentadas, na última parte, as conclusões deste estudo. 


\section{LEI DE RESPONSABILIDADE FISCAL: PRINCIPAIS DISPOSITIVOS}

A LRF instituiu no Brasil modificações substanciais nas regras de planejamento e controle das contas públicas, visando, primordialmente, à disciplina fiscal. Trata-se de uma lei de grande abrangência, dispondo e regulamentando aspectos tanto do controle das arrecadações quanto dos gastos governamentais, sendo que a sua implementação representa uma inflexão na forma como os governos devem lidar com a gestão e aplicação de recursos públicos. Vale destacar que a LRF é válida para todos os entes da federação e seus respectivos poderes executivo, legislativo e judiciário, além de todos os órgãos da administração indireta e empresas estatais dependentes de recursos públicos.

A LRF, basicamente, cria normas que: (i) melhoram a eficácia dos instrumentos orçamentários, como a Lei de Diretrizes Orçamentárias (LDO) e a Lei do Orçamento Anual (LOA) como mecanismos de planejamento da administração pública ; (ii) instituem mecanismos para o controle do déficit público e da dívida consolidada do setor público e (iii) aprimoram a transparência da gestão dos recursos públicos, facilitando o acesso, pela sociedade, às informações a respeito do desempenho fiscal dos governos. Neste trabalho, a atenção será voltada aos mecanismos de controle do déficit e do endividamento público.

O primeiro princípio da LRF a ser destacado é o estabelecimento de compromissos orçamentários e patrimoniais. Para tal princípio ter efeito um dos dispositivos inaugurado pela lei é o anexo de metas fiscais da LDO, no qual devem estar expressas, em valores correntes e constantes, as metas de arrecadação, despesas, resultado primário e nominal, montante da dívida pública e evolução do patrimônio líquido.

Desta forma, deve-se estabelecer uma programação da execução orçamentária por meio do desdobramento dessas metas anuais em metas bimestrais. Ao final de cada bimestre, caso a receita arrecadada seja menor que a receita prevista, impossibilitando a obtenção dos resultados primário e nominal estabelecidos, deve ser promovida, nos trinta dias subseqüentes, a limitação dos empenhos necessária para a recondução dos gastos para os resultados aprovados no anexo. Esta limitação de empenhos tem seus critérios especificados pela LDO, não podendo incluir as obrigações legais do ente e o serviço da dívida.

Deste conjunto de medidas pode-se extrair duas inferências básicas. Em primeiro lugar, a ocorrência de déficits primários no país está proibida, ou seja, no tocante aos gastos não-financeiros, não é permitido se gastar mais do que se arrecada. Além disso, há uma priorização do pagamento do serviço da dívida, medida coerente com um dos objetivos da lei, que é a estabilização da evolução do estoque da dívida do setor público.

Outro princípio que a lei consagra é o da compensação. Assim, a LRF rege que toda a medida do poder público que promover uma queda de arrecadação deve ser combinada com uma medida compensatória. A concessão ou ampliação de incentivo fiscal e a renúncia de receita, por exemplo, devem ser acompanhadas da implementação destes mecanismos de compensação, que podem ser: aumento de receita proveniente de elevação de alíquotas, ampliação da base de cálculo de impostos, instituição de novos tributos ou contribuições e redução de outras despesas.

A mesma compensação é exigida para a instituição de despesas obrigatórias de caráter continuado, definidas como aquelas que impliquem execução por um período superior a dois exercícios. O mesmo princípio é adotado, também, para as despesas com a seguridade social, salvo exceções para os gastos que concedam benefícios a 


\section{PRÊMIO GESTÃO EMPRESARIAL- EMPRESA JR - LEI DE RESPONSABILIDADE FISCAL: CONDIÇÃO INSUFICIENTE PARA O AJUSTE FISCAL \\ Antônio Carlos de Azevedo Sodré}

quem merecer por direito, os que visam à expansão quantitativa dos serviços prestados e os que reajustam o valor dos benefícios, a fim de manter seu valor real.

A LRF estabelece limites para a despesa com pessoal, definindo, inclusive, como deve ser feito o cálculo do total desta despesa. A despesa total com pessoal, a cada período, não pode ser superior a um certo percentual da receita corrente líquida, sendo que qualquer aumento nesta despesa tem o mesmo tratamento de uma despesa obrigatória de caráter continuado. Neste sentido, a LRF revoga a Lei Camata I e II.

Se o princípio do estabelecimento de compromissos orçamentários procura corrigir desvios no presente, os mecanismos de compensação impedem que a administração pública crie despesas que possam comprometer a gestão financeira nos próximos períodos.

Outro princípio que deve ser destacado é o da "regra de ouro". A lei estabelece que nenhuma operação de crédito pode ser utilizada para financiar despesas de custeio . Portanto, os montantes das operações de crédito não podem mais ultrapassar o volume das despesas de capital .

A LRF determina ainda que o Congresso Nacional deverá estabelecer os limites para a dívida pública, sendo esses limites uma proporção da receita corrente líquida do ente. Cada ente da federação deve fazer uma verificação quadrimestral de sua dívida, dispondo de três quadrimestres para efetuar a correção no caso do limite fixado ter sido ultrapassado. Enquanto a dívida não retornar ao limite estabelecido, o ente estará proibido de realizar qualquer operação de crédito, com exceção daquelas referentes ao refinanciamento do principal da dívida mobiliária, e de receber qualquer transferência voluntária de outra unidade federativa.

Analisando estes princípios da lei, pode-se perceber o que é entendido como disciplina fiscal. Em primeiro lugar, a LRF determina regras e limites para os gastos não-financeiros dos governos, preocupação esta de caráter intertemporal. Por isso, a importância dos mecanismos de compensação para evitar que sejam criadas despesas de difícil redução, depois de estabelecidas, como as despesas com pessoal, previdenciária e de caráter continuado, sem o planejamento de seu impacto no futuro e implementação da compensação necessária para manter o equilíbrio fiscal.

Outro aspecto que a lei apresenta é o de tentar impor restrições ao aumento demasiado da dívida pública. Para isto, é estabelecida uma série de restrições a operações de crédito e dada responsabilidade, ao Executivo e Legislativo da União, na fixação dos limites para esta dívida. Além disso, fica estabelecido que os governos devem priorizar o pagamento do serviço da dívida, com severas sanções para aquelas unidades federativas cujo estoque de dívida ultrapasse os limites estabelecidos.

A última questão a ser destacada é que a LRF busca a coordenação das políticas físcais das diversas unidades federativas. Esse é um caráter fundamental para se entender os objetivos da lei, pois busca-se evitar que a política fiscal implantada pelo governo central seja enfraquecida por uma gestão fiscal que siga outros parâmetros e princípios por parte de Estados e Municípios. Esse é um dos motivos para que a LRF abranja todas as unidades federativas.

Vistos estes princípios, a próxima parte deste trabalho procura ressaltar os conceitos e variáveis econômicas relevantes na análise dos resultados fiscais do setor público, relacionando-os com os dispositivos impostos pela lei. 


\section{REFERENCIAL TEÓRICO DE ANÁLISE}

Apesar de recentemente muitos trabalhos terem surgido tratando do problema do ajuste fiscal, como GIAMBIAGI (2001) e AFONSO (1998 e 1999), poucos se preocuparam em definir conceitualmente o que é ajuste fiscal, ou qual é a referência para que se afirme que um país conseguiu tornar suas contas ajustadas.

No debate econômico no final dos anos 90, a obtenção de bons "fundamentos macroeconômicos" era apontada como essencial para a manutenção da estabilidade e para gerar um novo ciclo de crescimento para o país. Dentre esses "fundamentos" o superávit primário era visto como um bom sinal de controle sobre os gastos públicos. Como assinala SANTOS (2000, p.50), "dez entre dez analistas do mercado financeiro e empresários nacionais e internacionais ligam diretamente o problema do ajuste fiscal à redução dos gastos públicos em bens e serviços". Porém, este indicador não é suficiente para julgar uma política fiscal prudente se não for acompanhado de uma análise mais profunda de outros fatores.

De qualquer forma, o argumento teórico dos defensores do ajuste fiscal pode ser resumido de forma bastante simples. Leva-se em consideração que se um governo praticar uma política fiscal expansionista por muito tempo há um aumento da relação Dívida/PIB. Esse crescimento, a partir de certo ponto, passa a ser considerado, pelos investidores, como sinal de que o país pode vir a não ter como honrar seus compromissos. Os agentes privados passam, então, a exigir taxas de juros maiores para aceitar os papéis do governo, devido ao aumento do risco de inadimplência.

Entretanto, um aumento nas taxas de juros leva a uma deterioração fiscal por dois motivos: em primeiro lugar, um aumento dos juros diminui o nível de atividade econômica, o que leva a uma queda na arrecadação e aumento na demanda por gastos sociais, como por exemplo o seguro-desemprego. Além disso, tem-se um impacto direto na despesa com o serviço da dívida.

Esse processo pode levar a um círculo vicioso no qual maiores taxas de juros são requeridas pelos investidores pelo aumento do risco-país, ao mesmo tempo que a elevação das mesmas dificulta a obtenção de superávits primários expressivos, necessários para a estabilização da relação Dívida/PIB.

Portanto, a variável chave no processo de avaliação da política fiscal pelos investidores é a relação Dívida Pública/PIB. Manter esta relação estável ao longo do tempo, ou pelo menos evitar que esta apresente um crescimento explosivo, é essencial para evitar dificuldades na rolagem da dívida, e suas conseqüências econômicas. Consequentemente, essa relação deveria ser a medida do ajuste fiscal de um país.

Por tal motivo, deve-se julgar o superávit primário pela sua capacidade de manter a relação Dívida/PIB estável. Considerando-se $S$ o superávit primário, $B$ o estoque da dívida pública, $r$ a taxa real de juros e $g$ a taxa real de crescimento do PIB, temos que a expressão que estima o superávit primário necessário para a estabilização da relação Dívida/PIB é :

$$
S=B(\mathrm{r}-\mathrm{g})
$$

Esta expressão pode ser obtida derivando no tempo a relação Dívida/PIB, levando em conta as definições de Necessidades de Financiamento Público e de despesa líquida com juros da dívida pública. 


\section{PRÊMIO GESTÃO EMPRESARIAL- EMPRESA JR - LEI DE RESPONSABILIDADE FISCAL: CONDIÇÃO INSUFICIENTE PARA O AJUSTE FISCAL \\ Antônio Carlos de Azevedo Sodré}

Assim sendo, quanto maior for o estoque da dívida, maior é o serviço de juros que esta dívida gera em um determinado momento. Portanto, se a relação Dívida/PIB crescer demasiadamente em um período, ceteris paribus, maior será o superávit primário que estabilizará a relação no período seguinte.

Quanto maior for a taxa de crescimento do PIB, logicamente, menor o superávit necessário para a estabilização da relação. Além disso, como já foi destacado, um aumento da atividade econômica gera um aumento da arrecadação e uma diminuição relativa dos gastos sociais, facilitando a obtenção de maiores superávits primários.

A relação entre taxas de juros e o superávit primário que estabiliza a Dívida/PIB, por sua vez, é bastante simples. Quanto maior a taxa de juros que incidir sobre o estoque da dívida, maior a despesa de juros que esta gera e, consequentemente, maior o superávit primário necessário para estabilizar a dívida.

Considerando-se que a medida correta do ajuste fiscal é a evolução da Dívida/PIB, pode-se concluir que a obtenção desse ajuste não é apenas resultado exclusivo da política fiscal. Tanto o crescimento da economia, quanto a taxa de juros resultante da política monetária, afetam as condições para que o ajuste fiscal seja realizado.

A LRF, como demonstrado na seção anterior, privilegia o controle dos gastos não-financeiros, portanto assegura a obtenção de superávits primários. No entanto, nada garante que esses superávits primários sejam suficientes para estabilizar a relação Dívida/PIB.

Pode-se argumentar que a LRF também estabelece limites para a dívida pública. Mas como foi ressaltado estes limites são fixados como uma proporção da receita corrente líquida (RCL) do ente. Por isso, é totalmente plausível que um aumento da carga tributária, em uma situação de baixo crescimento econômico, possa diminuir a relação Dívida/RCL ao mesmo tempo que cresce a relação Dívida/PIB. Mesmo considerando-se, por hipótese, uma forte correlação positiva entre o crescimento da RCL e o crescimento do PIB, altas taxas de juros, por exemplo, poderiam fazer com que superávit primário que estabilize as duas relações fosse insustentável social e politicamente e, portanto, impraticável.

Por isso é imprescindível analisar a dinâmica dos gastos financeiros e não-financeiros do setor público, visto que esta dinâmica acaba por determinar a evolução da Dívida Pública/PIB. Esta análise é feita na próxima seção.

\section{EVOLUÇÃO DA DÍVIDA PÚBLICA BRASILEIRA DURANTE O PLANO REAL}

A Dívida Líquida do Setor Público (DLSP), que inclui o Governo Central, Banco Central, Estados, Municípios e Estatais, apresentou um crescimento elevado desde o lançamento do Plano Real. Em 1994, essa dívida representava 30,38\% do PIB. Em julho de 2001 este número foi de 52,82\%, ou seja, no período analisado o crescimento da relação DLSP/PIB foi de aproximadamente $73 \%$. 
Tabela 1 - Dívida Líquida do Setor Público/PIB

\begin{tabular}{|l|l|l|l|l|}
\hline Ano & Governo & Governos & Empresas & Setor Público \\
& Federal e Banco & Estaduais & Estatais & \\
\hline 1994 & $13,06 \%$ & Municipais & & \\
\hline 1995 & $13,37 \%$ & $10,72 \%$ & $6,74 \%$ & $30,38 \%$ \\
\hline 1996 & $15,85 \%$ & $11,52 \%$ & $5,86 \%$ & $30,83 \%$ \\
\hline 1997 & $18,67 \%$ & $12,90 \%$ & $2,76 \%$ & $33,23 \%$ \\
\hline 1998 & $25,01 \%$ & $14,16 \%$ & $2,56 \%$ & $41,73 \%$ \\
\hline 1999 & $30,23 \%$ & $16,33 \%$ & $2,83 \%$ & $49,39 \%$ \\
\hline 2000 & $30,98 \%$ & $16,27 \%$ & $2,18 \%$ & $49,43 \%$ \\
\hline $2001 *$ & $32,55 \%$ & $17,90 \%$ & $2,37 \%$ & $52,82 \%$ \\
\hline Estoques em dezembro & & & & \\
\hline
\end{tabular}

Fonte: BANCO CENTRAL DO BRASIL (2001)

A causa deste grande crescimento pode ser atribuída à elevação dos gastos financeiros do governo, gerados pela combinação de: (i) altas taxas reais de juros praticadas desde o início do plano, (ii) baixos índices de crescimento econômico no período analisado e (iii) consideráveis déficits primários do setor público entre 1995 e 1998.

Desde o início do plano, a economia brasileira convive com altas taxas de juros. Em um primeiro estágio, a manutenção das taxas de juros em níveis elevados foi uma parte constitutiva do programa de estabilização, sendo uma contrapartida da ancoragem cambial. Nesta fase, a criação de um diferencial entre as taxas de juros interna e externa era essencial para a manutenção do sistema de bandas cambiais, que vigorou entre 1995 e 1999, pois gerava um fluxo de investimentos estrangeiros que sustentava o déficit em transações correntes resultante da fixação cambial. A partir de 1999, mesmo com o fim do sistema de bandas cambiais e a desvalorização, os insistentes déficits em transações correntes fizeram necessária a continuidade da política de altas taxas de juros. Não se pode descartar, desta forma, o papel dos juros internos no crescimento da dívida pública. 
O impacto dessas taxas é ainda maior se for considerada a recente mudança no perfil do endividamento público brasileiro. A primeira modificação diz respeito à participação da dívida interna e externa no total da DLSP. Em 1990, 56\% da DLSP correspondia à dívida externa e 44\% era relativo à dívida interna. Após 1992 esta relação começou a se inverter. Em 1995, a participação da dívida interna chegava a 81,6\% do total da DLSP, percentual que vem se mantendo, apesar das oscilações, até o presente momento. Assim sendo, a dívida interna é majoritária no endividamento público.

Tabela 2 - Participação do endividamento interno e externo no total da Dívida Líquida do Setor Público

\begin{tabular}{|l|l|l|}
\hline Ano & Participação da Dívida & Participação da Dívida \\
& Pública Interna & $28,94 \%$ \\
\hline 1994 & $71,06 \%$ & $18,36 \%$ \\
\hline 1995 & $81,64 \%$ & $11,71 \%$ \\
\hline 1997 & $88,29 \%$ & $12,46 \%$ \\
\hline 1998 & $87,54 \%$ & $15,49 \%$ \\
\hline 2000 & $84,51 \%$ & $21,05 \%$ \\
\hline $2001 *$ & $78,95 \%$ & $19,78 \%$ \\
\hline$*$ Até julho & $80,22 \%$ & $19,70 \%$ \\
\hline
\end{tabular}

Fonte: BANCO CENTRAL DO BRASIL (2001)

A dívida pública interna, por sua vez, é formada preponderantemente pela Dívida Pública Mobiliária Federal (DPMF), sendo que esta participação vem crescendo ao longo da década. A relação DPMF/DLSP aumentou de 39\% em 1994 para 65\% em 1996, 86\% em 2000 até chegar a 90\% no ano de 2001.

A DPMF apresentou drásticas alterações na participação dos diversos títulos que a compõem desde a constituição do Plano Real. Em 1994 os títulos pré-fixados representavam 40,2\% do total da DPMF. No mesmo ano, os títulos indexados à Selic e os títulos cambiais respondiam, conjuntamente, por $24,30 \%$ do total da DPMF. Em 2001, os títulos "selicados" e os títulos cambiais representam, respectivamente, $52,4 \%$ e $27,2 \%$ dos títulos federais em poder do público, sendo que os títulos pré- 
fixados constituem apenas 10,0\% deste total. Consequentemente, o serviço da dívida gerado pela DPMF tornou-se muito mais sensível às variações nas taxas de juros e às desvalorizações cambiais.

Tabela 3 - Dívida Pública Mobiliária Federal: Porcentagem dos principais Títulos em relação ao total da dívida

\begin{tabular}{|l|l|l|l|l|l|l|l|l|}
\hline Ano & Câmbio & TR & IGP-M & Selic & IGP-DI & Pré-Fixado & TBF & TJLP \\
\hline 1994 & $8,30 \%$ & $23,00 \%$ & $12,50 \%$ & $16,00 \%$ & - & $40,20 \%$ & - & - \\
\hline 1995 & $5,30 \%$ & $9,00 \%$ & $5,30 \%$ & $37,80 \%$ & - & $42,60 \%$ & - & - \\
\hline 1996 & $9,40 \%$ & $7,90 \%$ & $1,80 \%$ & $18,50 \%$ & - & $61,00 \%$ & - & $1,40 \%$ \\
\hline 1997 & $15,40 \%$ & $8,00 \%$ & $0,30 \%$ & $34,80 \%$ & - & $40,90 \%$ & - & $0,60 \%$ \\
\hline 1998 & $21,00 \%$ & $5,40 \%$ & $0,30 \%$ & $69,10 \%$ & $0,10 \%$ & $3,40 \%$ & $0,50 \%$ & $0,20 \%$ \\
\hline 1999 & $24,20 \%$ & $3,00 \%$ & $0,30 \%$ & $61,10 \%$ & $2,10 \%$ & $9,20 \%$ & - & $0,10 \%$ \\
\hline 2000 & $21,70 \%$ & $4,66 \%$ & $1,56 \%$ & $52,35 \%$ & $4,31 \%$ & $15,40 \%$ & - & $0,02 \%$ \\
\hline $2001 *$ & $27,20 \%$ & $3,80 \%$ & $3,42 \%$ & $52,40 \%$ & $3,15 \%$ & $10,03 \%$ & - & - \\
\hline
\end{tabular}

Fonte: BANCO CENTRAL DO BRASIL (2001)

Essa alteração no perfil da DPMF é um indicador do maior risco associado ao país e da percepção, por parte dos investidores, que as políticas cambiais e monetárias estão sujeitas a oscilações ao longo do tempo.

Pelo quadro descrito acima é correto afirmar que não somente as altas taxas de juros tiveram um importante papel no crescimento da dívida pública, como o impacto da manutenção destas taxas tendeu a ser muito maior na geração de despesas com juros desta dívida, devido às modificações apresentadas no perfil do endividamento durante a década de 90.

Não pode ser desconsiderado desta análise o fato da economia brasileira ter apresentado modestas taxas de crescimento desde 1995. A variação média do PIB, em termos reais, não passou de 2,6\% (IBGE, 2001) nos últimos 6 anos e as previsões para o ano de 2001 não ultrapassam 2,5\%. Como foi afirmado na seção anterior, um baixo nível de atividade não só contribui para o aumento da relação Dívida/PIB, como dificulta a geração de superávits primários em um montante necessário para estabilizar esta relação.

O aumento da dívida pública no período analisado também se deveu a uma política fiscal expansionista durante os primeiros anos de implantação do Plano Real. Entre 1995 e 1998 o superávit primário médio acumulado pelo governo federal (incluindo o Banco Central) foi de apenas $0,30 \%$ do PIB, sendo que no ano de 1997 ocorreu um déficit primário de 0,23\% do PIB. Estados e Municípios obtiveram, neste mesmo período, resultados primários que podem ser considerados tão ruins quanto os do governo 
Central, apresentando um déficit médio, entre 1995 e 1998, de 0,34\% do PIB. Nestes anos, como resultado das políticas fiscais do governo central, Estados, Municípios e estatais , o setor público como um todo obteve um déficit primário médio de $0,20 \%$ do PIB. Deve-se levar em conta também o fato de que, com as privatizações, o déficit gerado pelas estatais decaiu consideravelmente neste período.

Tabela 4 - Necessidades de Financiamento do Setor Público (\% PIB) - Primário

\begin{tabular}{|l|l|l|l|l|}
\hline Ano & Estados e Municípios & Estatais & Governo Central e Banco Central & Setor Público \\
\hline 1994 & $-0,77 \%$ & $-1,19 \%$ & $-3,25 \%$ & $-5,21 \%$ \\
\hline 1995 & $0,18 \%$ & $0,07 \%$ & $-0,52 \%$ & $-0,27 \%$ \\
\hline 1996 & $0,54 \%$ & $-0,08 \%$ & $-0,37 \%$ & $0,09 \%$ \\
\hline 1997 & $0,45 \%$ & $0,18 \%$ & $0,24 \%$ & $0,87 \%$ \\
\hline 1998 & $0,19 \%$ & $0,35 \%$ & $-0,55 \%$ & $-0,01 \%$ \\
\hline 1999 & $-0,22 \%$ & $-0,66 \%$ & $-2,36 \%$ & $-3,24 \%$ \\
\hline 2000 & $-0,55 \%$ & $-1,07 \%$ & $-1,88 \%$ & $-3,50 \%$ \\
\hline$(-)$ superávit & & & & \\
\hline
\end{tabular}

Fonte: BANCO CENTRAL DO BRASIL (2001)

Como sugere a análise feita em CIRNE DE TOLEDO (1998), a política fiscal pode ser considerada inadequada neste período, pois o expansionismo desta política foi decisivo no crescimento da dívida pública. $O$ fato é que, dada uma política de estabilização baseada em altas taxas de juros e contenção da demanda, a política fiscal expansionista do governo teve um papel crucial na aceleração do crescimento da dívida pública, que passou de 30,8\% em 1995 para 41,73\% em 1998, sendo que o aumento do estoque da dívida neste período fez com que o volume do serviço da dívida fosse maior nos anos posteriores.

Em 1999, como já foi destacado na introdução deste trabalho, o governo central recuperou o controle sobre os gastos não-financeiros. Em média, entre 1999 e 2000, a União, incluindo o Banco Central, obteve um superávit primário de 2,11\% do PIB. Em 2001, já com a LRF plenamente em vigor, os indicadores apontam para a manutenção deste nível de resultados primários.

Entre 1999 e 2000, o superávit primário médio de Estados e Municípios foi de 0,10\% do PIB, o que mostra que também houve uma recuperação no controle dos gastos não-financeiros nestes níveis de governo. É preciso lembrar que em 1999, a maioria dos Estados já tinha renegociado suas dívidas com a União. Nestes acordos, os Estados comprometeram-se a gerar superávits primários condizentes com o pagamento das parcelas da dívida renegociada com o governo federal.

O setor público como um todo, incluindo as estatais, obteve um superávit médio, nesses dois anos, de 3,36\% do PIB. Em 2001, os resultados primários apontam para superávits bastante semelhantes. Porém, 
mesmo estes superávits não contiveram a elevação da dívida pública, que aumentou sua proporção do PIB de 48,20\%, no fim de 1998, para 52,50\% em 2001. Além da elevação das taxas de juros em resposta à crise cambial de 1999, o estoque de dívida acumulado nos anos anteriores e o pequeno crescimento do PIB no período elevaram o superávit necessário para a estabilização da Dívida/PIB para níveis acima dos resultados obtidos pelo setor público.

A retórica do governo central sempre apontou como grande vilão do processo de ajuste fiscal brasileiro os gastos com pessoal e com benefícios da previdência. "O desequilíbrio nas contas previdenciárias tem sido o principal fator de agravamento dos resultados fiscais do setor público" (MINISTÉRIO DA FAZENDA, 1998). Todavia, um exame nos dados de forma mais detalhada não permite qualquer inferência neste sentido. Em 1994 as despesas com pessoal e benefícios previdenciários correspondiam a $52,76 \%$ da receita conjunta do tesouro e da previdência. Este percentual aumentou para 56,22\% em 1997, porém reduziu-se para 51,54\% em 2000, um percentual abaixo do encontrado em 1994. Portanto, esse tipo de gasto não pode ser responsabilizado pelo crescimento da dívida pública, principalmente nos últimos anos.

Como assinala SANTOS (2000, p.88), o governo federal não só privatizou grande parte das empresas públicas federais como estimulou os Estados a privatizarem seus ativos de grande porte: "Em particular, nos principais contratos de renegociação das dívidas estaduais foram impostas condições que praticamente obrigavam os estados a vender, ou transferir para a União para privatização posterior, ativos em valores muito expressivos, como condição para a obtenção de condições mais favoráveis para o contrato de refinanciamento."

Em 1998 os resultados obtidos pelas privatizações federais e estaduais, incluindo as receitas auferidas e as dívidas transferidas, alcançaram 4,83\% do PIB. Em 1997, o mesmo resultado representou 3,44\% do PIB. Todavia, o fato desses expressivos resultados não terem sido suficientes para estabilizar a relação DLSP/PIB, confirma a importância maior dos outros fatores que estão sendo considerados neste trabalho para explicar este crescimento. Não se pode desprezar, entretanto, o papel das privatizações na redução da velocidade de crescimento da dívida, visto que 84,9\% dos recursos efetivamente recebidos pelo governo federal no processo de privatizações foram utilizados para o abatimento da mesma.

Por fim, para corroborar a análise que vem sendo feita, os gastos com juros reais do setor público elevaram-se de forma consistente ao longo do Plano Real. Em 1994, esses gastos representavam 3,92\% do PIB. Em 1998, já pelo reflexo do aumento do estoque da dívida no período anterior e do aumento da taxa de juros, este percentual subiu para 7,51\% do PIB. Atualmente, o gasto com juros reais representa $6,58 \%$ do PIB. O crescimento deste tipo de gasto, por sua vez, confirma o fato de que o esforço fiscal necessário para gerar excedentes para o pagamento com juros da dívida é muito superior hoje em relação ao início do Plano Real.

Portanto, os dados referentes às contas públicas no decorrer do Plano indicam que o grande responsável pelo aumento da dívida pública, pelo menos a partir de 1999, foram os gastos financeiros do setor público, que foram elevados consideravelmente pelas políticas de altas taxas de juros combinadas com a mudança no perfil da dívida pública e o crescimento do próprio estoque da dívida ao longo do Plano Real. 


\section{CONCLUSÕES}

É importante que a discussão sobre o ajuste fiscal brasileiro seja fundamentada na avaliação da evolução da DLSP/PIB. O Brasil, neste sentido, vive um quadro demasiadamente perigoso, pois esta relação tem crescido de forma consistente ao longo do Plano Real.

Esse grande risco se apresenta pois, caso não sejam tomadas as medidas necessárias para a estabilização do crescimento da dívida, o país pode encontrar sérias dificuldades no refinanciamento dos títulos públicos, principalmente sob o atual contexto de instabilidade nos mercados financeiros internacionais. Se a trajetória da relação Dívida/PIB não for contida, pode-se gerar uma situação na qual, mais do que nunca, "os credores e investidores exigem juros altos demais e com isso provocam o déficit que os assusta, justificando o refinanciamento dos títulos a um custo exorbitante!"(BATISTA JR, 2000. p.132), colocando em risco, inclusive, a própria estabilização, na medida que este processo pode aumentar a pressão para que o financiamento dos títulos seja realizado pela expansão monetária.

Atualmente, como demostra o breve exame das contas públicas apresentado neste estudo, o principal responsável pela elevação da dívida pública são os gastos financeiros do setor público. Portanto, no caminho que leva ao ajuste fiscal, devem ser adotadas medidas que contribuam para a redução destes gastos. Neste conjunto de medidas, destacam-se aquelas destinadas à redução das taxas reais de juros na economia.

A dinâmica da taxa de juros interna, atualmente, é determinada pelo desequilíbrio nas contas externas do país. A necessidade de financiar os déficits em transações correntes, em um contexto de maior instabilidade nos fluxos de investimento estrangeiros, faz com que o Banco Central mantenha um elevado diferencial entre as taxas de juros interna e externa, gerando o fluxo de recursos externos necessários para o financiamento do déficit na conta corrente do Balanço de Pagamentos.

É por isso que para conseguir diminuir as atuais taxas de juros são necessárias medidas que caminhem no sentido de diminuição do déficit em transações correntes para níveis que permitam um financiamento mais tranqüilo do mesmo. Como exemplo, poderiam ser citadas a necessidade de uma política comercial mais ativa e de reformas internas no sentido de aumentar a competitividade das empresas brasileiras no exterior, incluindo as reformas tributária e do mercado de capitais brasileiro . Essas medidas contribuiriam para a obtenção de superávits na balança comercial e, consequentemente, poderiam implicar a redução do déficit em Conta Corrente.

A diminuição da taxa de juros teria um impacto duplo na evolução da dívida pública. O primeiro deles decorreria da diminuição imediata do serviço da dívida, dado o perfil do endividamento que é altamente sensível a alterações nas taxas de juros, diminuindo o tamanho do superávit que estabiliza a relação DLSP/PIB. O segundo deles viria por meio da reativação da atividade econômica, resultando no aumento da capacidade do governo em gerar superávits primários necessários para a estabilização da relação Dívida/PIB, seja pelo aumento da arrecadação ou pela diminuição da demanda por gastos sociais.

Portanto, é preciso compreender que a questão do ajuste fiscal não é exclusivamente assunto de política fiscal. Ela passa também, principalmente no caso brasileiro, por mudanças nas políticas monetária e comercial, além de envolver as reformas na estrutura econômica brasileira. 
A LRF criou normas que controlam os gastos nãofinanceiros do setor público. Como foi apresentado neste artigo, os gastos não-financeiros tiveram grande importância no crescimento da dívida nos primeiros anos do Plano Real. Neste aspecto a LRF é um instrumento extremamente positivo para o ajuste fiscal. Além disso, a LRF também impôs os mesmos critérios de gestão físcal para todos os níveis de governo. Isso é relevante se for considerado o fato de que o esforço fiscal de um nível de governo podia ser, completa ou parcialmente anulado pelos resultados primários dos outros níveis.

Entretanto, como procurou ser demonstrado neste estudo, mesmo com a adoção das medidas que a LRF impõe, o ajuste fiscal brasileiro não está assegurado. Apesar da lei procurar garantir a geração de fluxo financeiros capazes de manter a dívida em um nível prudente, como a fixação de limites da dívida como proporção da receita para todos os entes da federação, isto não garante que a relação Dívida/PIB se estabilize, pois na dinâmica da evolução desta relação entram fatores como a taxa de crescimento econômico e o nível de taxa de juros praticado pelo país. Portanto, é correto afirmar que a Lei de Responsabilidade Fiscal é uma condição necessária, mas não suficiente para o ajuste fiscal brasileiro.

\section{Artigo enviado em 10.05.2001. Aprovado em 20.04.02}

\section{REFERÊNCIAS BIBLIOGRÁFICAS}

AFONSO, José Roberto R.; MANOEL, Álvaro; TAVARES, Marcus Antonio R.. Uma Proposta para um novo regime fiscal no Brasil: o da responsabilidade fiscal. 1999. 22p. Disponível em: www.federativo.bndes.gov.brlestudos. Acesso em: 15 set. de 2001.

AFONSO, José Roberto R.; RAIMUNDO, Júlio César M.; ARAÚJO, Erika Amorim. Breves Notas sobre o Federalismo Fiscal no Brasil. 1998. 13 p.. Disponível em: www.federativo.bndes.gov.brlestudos. Acesso em: 15 set. de 2001.

BANCO CENTRAL DO BRASIL. Quadro estatístico do boletim do Banco Central do Brasil-agosto de 2001. 2001. Disponível em: www.bcb.gov.br. Acesso em: 15 de set. 2001.

BATISTA Jr., Paulo Nogueira. A economia como ela é... 1 ed. São Paulo: Boitempo, 2000. cap 3. p 107-133.

CIRNE DE TOLEDO, Joaquim Elói. Políticas Econômicas e Estabilização no Plano Real. Revista de Economia Aplicada. São Paulo, 1999, vol. 3, número especial, p 61 77, mar. 1999.

FIGUEIREDO, Carlos Maurício C.; NÓBREGA, Marcos Antônio Rios da. Lei de Responsabilidade Fiscal: aspectos gerais. 2000. 14 p. Disponível em: www.federativo.bndes.gov.brlestudos. Acesso em: 15 set. de 2001 .

FRANCO, Gustavo. Inserção externa e desenvolvimento. In: . O Desafio Brasileiro, 1 ed. São Paulo: editora 34, 2000.Cap 1.

GIAMBIAGI, Fábio. À procura de um consenso fiscal: o que podemos aprender da experiência internacional? Revista do BNDES, Rio de Janeiro, v. 8, no. 15, p. 65 102, jun. 2001.

GIAMBIAGI, Fábio. Necessidades de Financiamento do Setor Público: Bases para a discussão do ajuste fiscal no Brasil -1991/96. Texto para Discussão no. 53. Rio de Janeiro : BNDES, 1997. 36p. 


\section{PRÊMIO GESTÃO EMPRESARIAL- EMPRESA JR - LEI DE RESPONSABILIDADE FISCAL: \\ CONDIÇÃO INSUFICIENTE PARA O AJUSTE FISCAL \\ Antônio Carlos de Azevedo Sodré}

INSTITUTO BRASILEIRO DE ESTATÍSTICA E GEOGRAFIA - IBGE. Série histórica da variação real do PIB . Disponível em: www.ipeadata.gov.br . Acesso em: 15 de set. 2001.

KHAIR, Amir Antônio. Lei de Responsabilidade Fiscal: As transgressões à Lei de Responsabilidade Fiscal e as correspondentes punições fiscais e penais. 2000.107 p. Disponível em: www.federativo.bndes.gov.brlestudos . Acesso em: 15 set. de 2001.

MINISTÉRIO DA FAZENDA. Programa de Estabilidade Fiscal (Resumo). 1998. Disponível em: www.fazenda.gov.br/portugues/ajuste/respef.html. Acesso em: 15 de set. 2001.

SANTOS, Fábio Pereira dos. O Plano Real e o crescimento da dívida pública no Brasil. 2000.97 f. Dissertação (Mestrado em Administração Pública e Governo) Escola de Administração de Empresas de São Paulo, Fundação Getulio Vargas, São Paulo.

TRIBUNAL DE CONTAS DO ESTADO DO RIO GRANDE DO SUL. Lei de Responsabilidade Fiscal: Manual de Procedimentos para a aplicação da Lei de Responsabilidade Fiscal do Tribunal de Contas do Estado do Rio Grande do Sul. 2000. 118 p. Disponível em: www.federativo.bndes.gov.brlestudos. Acesso em: 15 set. de 2001. 